\title{
UM ESTUDO SOBRE GINÁSTICA LABORAL EM EMPRESAS DO INTERIOR DE SÃO PAULO
}

\section{A STUDY ABOUT LABOR GYMNASTICS IN COMPANIES OF COUNTRYSIDE OF SÃO PAULO}

\author{
Taisa Pierina - taisa_pierina@ hotmail.com \\ Angelita Moutin Segovia Gasparotto - angelita.gasparotto@ fatectq.edu.br \\ Faculdade de Tecnologia de Taquaritinga (FATEC) - SP - Brasil
}

DOI: 10.31510/infa.v15i2.491

\section{RESUMO}

Este trabalho tem como objetivo mostrar que cada vez mais as empresas buscam introduzir a Ginástica Laboral para a melhoria e qualidade de vida do trabalhador, estimulando sua capacidade e, aumentado a produtividade. Essa prática vem sendo adotada desde 1925 em alguns países, mas no Brasil foi inserida apenas em 1973. Estudos comprovam que essa atividade influencia na melhoria de Lesão por Esforços Repetitivos e Doenças Osteomusculares Relacionados ao Trabalho, diminui o estresse que são causados por ambientes de trabalho que há muita pressão. Com isso, foi elaborado um estudo de caso que mostra que as empresas do interior de São Paulo de ramos de atuação distintos buscam implantar essa prática em benefício a mesma e para o colaborador que apresenta melhoria no seu rendimento, contribuindo com a lucratividade da organização.

Palavras-chave: Ginástica Laboral. Lesão por Esforços Repetitivos. Doenças Osteomusculares Relacionados ao Trabalho. Produtividade.

\begin{abstract}
This work aims to show that more and more companies seek to enter the Labor Gymnastics for the improvement and quality of life of the worker, stimulating their capacity and increased productivity. This practice has been adopted since 1925 in some countries, but in Brazil was just entered in 1973. Studies have shown that this activity influences on the enhancement of injury due to repetitive strain and musculoskeletal diseases related to work, decreases stress which are caused by work environments that there is a lot of pressure. With this, it was elaborated a case study that shows that the companies of interior of São Paulo branches distinct looking to deploy this practice to the benefit of the same and to the employee who shows improvement in their income, thereby contributing to the profitability of the organization.
\end{abstract}

Keywords: Labor Gymnastics. Repetitive Strain Injury. Musculoskeletal Diseases Related to Work. Profitability. 


\section{INTRODUÇÃO}

Segundo E.F. CONFEF (2004) a Ginástica Laboral (GL) não é uma prática atual, em 1925 na Polônia ocorreu seus primeiros registros na qual operários se exercitavam com uma pausa adaptada a cada ocupação especifica, sendo assim conhecida como Ginástica de Pausa. Contudo, a Ginástica Laboral só se desenvolveu realmente no Japão, onde os funcionários dos Correios, desde 1928, frequentavam sessões de Ginástica Laboral diariamente, visando a descontração e o cultivo da saúde.

As primeiras manifestações de atividades físicas entre funcionários no Brasil foram em 1901, mas somente em 1973, teve a primeira proposta inicial publicada de GL entre funcionários. Algumas empresas perceberam a importância e resolveram investir em opções de lazer e esporte para seus funcionários. Um exemplo foi a Fábrica de Tecidos Bangu e o Banco do Brasil, com a criação da Associação Atlética do Banco do Brasil (SAMPAIO; OLIVEIRA, 2008).

Com toda essa evolução tecnológica, o sedentarismo tomou conta da rotina da sociedade, resultando em consequências negativas sobre a saúde da mesma. Práticas de incentivo são bem-vindas para estimularem o ambiente de trabalho, promovendo maior qualidade de vida ao colaborador e reduzindo custos em função do afastamento temporário ou permanente dos funcionários para o empreendedor (ROSSATO et al, 2013).

No Brasil, existem poucas dessas práticas para a melhoria na qualidade de vida dos trabalhadores e da população em geral. Apesar de as empresas oferecerem e tentarem incentivar seus colaboradores a se exercitarem fisicamente, oferecendo descontos em academias perto do local de trabalho, não há muita procura (MACIEL et al, 2005).

Com isso, algumas doenças vêm se agravando com o decorrer do tempo, que é o caso da Lesão por Esforços Repetitivos (LER) ou Distúrbio Osteomusculares Relacionados ao Trabalho (DORT) que, segundo Fundacentro (2007) são as designações que podem levar a ocorrência de afecções de músculos, tendões, sinóvias, nervos, fáscias e ligamentos, isoladas ou combinadas, com ou sem degeneração de tecidos. Elas atingem principalmente, mas não somente os membros superiores, região escapular (em torno do ombro) e região cervical. Têm origem ocupacional, e decorrem, de forma combinada ou não, do uso repetido ou forçado de grupos musculares e da manutenção de postura inadequada. 


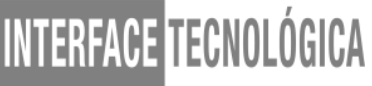

A importância da implantação da GL é o comprometimento que a Alta Direção deve ter em relação aos seus colaboradores, para que durante sua rotina de trabalho não haja desconforto em sua postura, melhorando e estimulando gradativamente o seu desempenho para a empresa. Para melhoria do colaborador no ambiente de trabalho, foi desenvolvida a Norma ISO 45001:2018, que está sendo válida desde maio deste ano e tem como foco promover e prevenir a saúde física e mental dos trabalhadores.

Esse artigo foi desenvolvido com base em dados de publicações anteriormente já pesquisados e tem como objetivo mostrar que mesmo na era do capitalismo e da industrialização, as empresas estão procurando investir cada vez mais na qualidade de vida de seus colaboradores, tendo em vista que estes são a base para contribuir com o lucro da organização.

Com isso, foi elaborada uma pesquisa de campo constituída por nove questões voltadas à implantação da GL nas empresas do interior de São Paulo de diversos setores e como a teoria se inter-relaciona com a prática.

\section{GINÁSTICA LABORAL}

\subsection{Objetivos}

Segundo Oliveira (2016), com toda essa evolução, aumento da produtividade e capitalismo são alguns fatores que contribuíram para uma jornada de trabalho mais longa, como consequência, horas extras, pressão para atingir as metas e objetivos da organização, gerando muita pressão sobre o funcionário. Muitas vezes, essas condições nem sempre são favoráveis e frequentemente desgastantes, deixando o colaborador desmotivado, cansado e contribuindo para o surgimento de doenças.

Contudo, os gerentes notaram uma perda no rendimento dos colaboradores em razão da baixa lucratividade e perceberam que estes são os grandes responsáveis pela produção e, assim, decidiram investir na GL, que contribui para o conforto e bem-estar do colaborador, reduzindo a taxa de absenteísmo e afastamentos por lesões, fazendo com que este contribua positivamente para a empresa (OLIVEIRA, 2016).

Picoli e Guastelli (2002) afirmam que alguns dos objetivos da Ginástica Laboral são:

- Reduzir a Fadiga Muscular;

- Promover a consciência corporal, a saúde e o bem-estar;

- Promover a integração entre os funcionários; 
- Reduzir o número de acidentes de trabalho;

- Aumentar a motivação e a disposição para o trabalho;

- Previnir doenças ocupacionais.

Para Lima (2003) GL refere-se a um conjunto de exercícios específicos que são realizados no próprio local de trabalho, atuando de forma preventiva e terapêutica, sem levar o colaborador ao cansaço por ser de curta duração, trabalhando-se o alongamento das estruturas musculares envolvidas nas tarefas operacionais diárias, visando ao relaxamento e diminuição do estresse por parte dos funcionários.

Após a implantação da GL na empresa, se obtém resultados a curto prazo e apresentam benefícios tanto para a organização quanto para o funcionário, tais como: diminuição de custos com assistência médica, redução nas faltas e aumento da produtividade (SAMPAIO; OLIVEIRA, 2008).

\subsection{Tipos de Ginástica Laboral}

Para Oliveira (2016), existem 3 tipos de GL que motivem e promovem a satisfação do trabalhador no seu ambiente de trabalho, sendo elas aplicadas das seguintes maneiras:

1. Ginástica Laboral Preparatória é feita no início do expediente para despertar, espreguiçar, aquecer o corpo e aliviar tensões acumuladas de uma noite mal dormida, aliviando o cansaço e renovando as energias do funcionário.

2. Ginástica Laboral Compensatória é feita no meio do expediente, dando uma pausa para o trabalhador se alongar e relaxar, para voltar com o corpo aliviado e sem fadiga.

3. Ginástica Laboral de Relaxamento é aquela feita no final do expediente para ajudar a relaxar a musculatura e alongar, promovendo um descanso maior para o funcionário.

\section{BENEFÍCIOS DA GINÁSTICA LABORAL}

Recentemente foi promovida a ISO 45001:2018 e a empresa deve ser certificada para que ela tenha um sucesso maior, além disso, a implantação dessa norma é uma estratégia para a empresa e depende de todos os níveis organizacionais. 


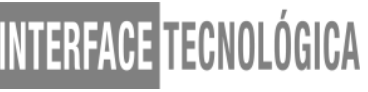

Quando um programa de GL é realizado de forma correta e acompanhada por profissionais capacitados, melhora a qualidade de vida e o bem-estar do colaborador, prevenindo algumas doenças causadas por má postura, esforços repetitivos e estresse, aumentando sua produtividade e disposição para realização da sua tarefa. Consequentemente, irá contribuir para a lucratividade da empresa e redução dos gastos com os funcionários que pediam afastamento regularmente (OLIVEIRA, 2016).

Os programas de GL promovem a saúde mental, física e social do indivíduo. Alguns de seus benefícios, estão listados a seguir:

Segundo Martins (2005) a prática da GL promove um acréscimo significativo da flexibilidade, combatendo o encurtamento muscular e, consequentemente, minimizando as dores musculares cotidianas dos colaboradores como:

\section{Fisiológicos}

- Possibilita melhor utilização das estruturas osteo-mio-articulares, como maior eficiência e menor gasto energético por movimento especifico;

- Promove o combate e prevenção das doenças profissionais;

- Promove o combate e prevenção do sedentarismo, estresse, depressão, ansiedade;

- Melhora da flexibilidade, força, coordenação, ritmo, agilidade e a resistência, promovendo uma maior mobilidade e melhor postura;

- Promove a sensação de disposição e bem-estar para a jornada de trabalho;

- Redução da sensação de fadiga no final da jornada;

- Contribui para a promoção da saúde e da qualidade de vida do trabalhador;

- Propicia através da realização dos exercícios características preparatórias, compensatórias e relaxantes no corpo humano;

- Bem como os principais benefícios fisiológico relacionados ao exercício sobre o sistema cardíaco, respiratório, esquelético, entre outros bem documentados nas evidências científicas;

\section{Psicológicos}

Segundo Mota (2002), sabe-se hoje que a prática de uma simples atividade física pode aumentar o rendimento profissional, a confiança, a capacidade para lidar com as emoções e o 


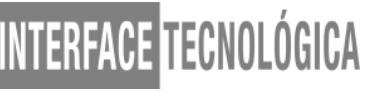

autocontrole, capacidade de raciocínio, memória, percepção, bem-estar, satisfação sexual e eficiência profissional; e também diminuir o absentismo, abuso de substâncias, irritabilidade e ansiedade,depressão e enxaquecas. Os Benefícios da GL envolvidos no programa são:

- Motivação por novas rotinas;

- Melhora do equilíbrio biopsicológico;

- Melhora da auto-estima e da auto-imagem;

- Desenvolvimento da consciência corporal;

- Combate as tensões emocionais

- Melhora da atenção e concentração as atividades desempenhadas sociais

- Favorece o relacionamento social e trabalho em equipe;

- Melhoria das relações interpessoais;

\section{Sociais}

Duarte (2000), quando se implanta um programa de GL numa empresa, envolve-se a coletividade, o que propicia, além dos benefícios físicos em si, momentos de descontração e um desligamento momentâneo dos problemas do trabalho, se tornando uma ocasião de pausa. Independentemente de suas responsabilidades, naquele instante todos irão relacionar-se, praticar exercícios, cooperar uns com os outros, descobrirem suas necessidades e limitações, respeitando seus limites e os de seus colegas sendo evidenciado também:

- O surgimento de novas lideranças;

- Favorece o contato pessoal;

- Promove a interação social;

- Favorece o trabalho em equipe;

- Melhora as relações interpessoais

\section{Empresarias}

Para Militão (2001), benefícios empresariais através de resultados positivos como: aumento da produtividade, a redução de algias e do desânimo, diminuição dos afastamentos por doenças ocupacionais e das ausências no trabalho, por consequiência aos efeitos de descontração, relaxamento e ainda eliminação de dores proporcionadas pela GL. Os benefícios são: 
- Redução dos gastos com afastamento e substituição de pessoal;

- Diminuição de queixas, afastamentos médicos, acidente e lesões;

- Melhoria da imagem da instituição junto aos empregados e a sociedade;

\section{PROCEDIMENTOS METODOLÓGICOS}

Para o desenvolvimento deste trabalho, realizaram-se dois tipos de pesquisa: a pesquisa bibliográfica, com objetivo de compreender a história da ginástica laboral, seus benefícios e objetivos para a saúde do trabalhador e, a pesquisa de campo, com o intuito de verificar se empresas do interior de São Paulo têm a GL implantada. A pesquisa foi realizada via e-mail com três empresas que se disponibilizaram a auxiliar o autor deste trabalho.

\section{EMPRESAS QUE RESPODERAM O QUESTIONÁRIO}

A empresa $\mathrm{X}$ atua no setor de alimentos, sendo uma das principais indústrias deste ramo no Brasil e é líder em segmento de doces e vice no segmento de atomatados em stand-up. A empresa apresenta um amplo mix de produtos, composto por mais de 250 itens, dentre molhos, atomatados, vegetais em conserva, condimentos, doces, geleias, gelatinas, achocolatados em pó, sopas e macarrão instantâneo.

Todos os processos de fabricação podem ser verificados pelos clientes, pois as embalagens possuem um código que permite rastrear as informações referentes ao produto.

Essa empresa opera dentro dos padrões nacionais e internacionais de acordo com a legislação vigente e é auditada periodicamente por empresas e órgãos reconhecidos mundialmente.

Já a empresa Y é atuante no mercado desde 1969, projetando tudo sobre aviação com a mais alta tecnologia. Ela é fruto de um produto da perseverança e da determinação, é uma combinação da tecnologia mais avançada com as paixões. E, assim, há quase 50 anos, criamos, desenvolvemos, produzimos e entregamos mais de 8 mil aeronaves.

E por fim, a empresa $\mathrm{Z}$ está inserida no mercado há 28 anos, sendo reconhecida por seus mais de 320 clientes. Uma empresa nacional de Tecnologia de Informação e Automação atua em todo território brasileiro por meio de vários canais de venda e suporte. 


\section{RESULTADO E DISCUSSÃO}

As empresas estão buscando cada vez mais práticas de incentivo para a melhoria de vida dos seus funcionários. Após os conceitos estudados e analisados, foi desenvolvido um questionário que contém nove questões (sendo cinco de alternativas e quatro em aberta) voltadas para a qualidade do funcionário no ambiente de trabalho, avaliando sua produtividade e qual o interesse do empresário em implementar a GL. Esse questionário foi aplicado em três empresas, por meio de comunicação remota, com o objetivo de analisar as diferenças existentes entre elas. As empresas estão enquadradas no setor de aviação, tecnologia e alimentício. Portanto, a pesquisa consegue fornecer aos pesquisadores resultados das diversas áreas.

Quadro 1 - Questionário adotado para a realização da pesquisa

1. Qual a frequência de faltas do seu funcionário devido à enfermidade?

( ) Semanalmente

( ) Quinzenalmente

( ) Mensalmente

2. É verificado se essa falta é por Lesão por Esforços Repetitivos (LER)?

( ) Sim

( ) Não

3. Quando essa enfermidade é por lesão, a empresa toma alguma providência? Qual?

\section{A empresa pensa na prevenção dessa LER? Como?}

5. Uma das possíveis prevenções é a Ginástica Laboral. Ela é aplicada aos colaboradores?

( ) Sim

6. Se a sua resposta anterior foi sim, você acha benéfica para a produtividade do seu funcionário?

7. Se a sua resposta da pergunta 5 foi não, você tem interesse em implantar a ginástica laboral na sua empresa?

8. Se você não tem interesse, por qual motivo não implanta?

9. Se você tem interesse, por que ainda não implantou?

\section{Fonte: Autoria Própria (2018)}

Com base nas respostas obtidas, pode-se notar que as empresas tinham problemas com faltas por enfermidades, entretanto não são todas que buscaram verificar se essas ausências ocorriam por doenças ocupacionais 


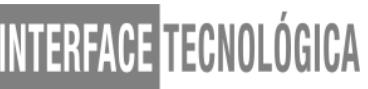

Todas as empresas pesquisadas responderam que esses profissionais são devidamente atendidos por médicos e após constatado o problema, são afastados até a recuperação.

A empresa X, Y e Z adotam medidas para evitar esse tipo de problema, como a Ginástica Laboral, massoterapeura, campanhas de saúde e segurança no trabalho e a disponibilidade de equipamentos adequados.

\section{CONCLUSÃO}

Pode se concluir, com os resultados obtidos desse questionário, que atualmente as empresas, independente do ramo de atuação, buscam a melhoria e qualidade de vida do seu colaborador. Portanto, uma das maneiras mais eficazes é a implantação da GL, pois previne doenças como a LER e DORT, diminuição do estresse que prejudica a saúde do funcionário, fazendo com que ele tenha uma perda no seu rendimento e assim diminuindo significativamente a lucratividade para a empresa. Como apresentado no trabalho, a GL é uma prática benéfica tanto para a empresa quanto para o funcionário e mesmo que as empresas não tenham esse método adotado, empresários estão buscando aderir ao ambiente de trabalho dos seus colaboradores.

\section{REFERÊNCIAS}

ASSOCIAÇÃO BRASILEIRA DE NORMAS TÉCNICAS. ISO 45001: Sistema de gestão de saúde e segurança ocupacional Requisitos com orientação para uso. Rio de Janeiro: ABNT, Maio 2018.

DUARTE, M. F. Efeitos da ginástica laboral em servidores da Reitoria

da UFSC. In: Revista Brasileira de Ciência e Movimento, Brasília, v.8,n.4, p.07- 13, set. 2000.

EF. CONFEF. Ginástica Laboral. Agosto, nº 13, p.6-11, 2004.

FUNDACENTRO. Ministério do Trabalho e Emprego. LER/ DORT. Disponível em: <http://www.fundacentro.gov.br/>. Acesso em 26 de novembro de 2018.

LIMA, V. "Ginástica Laboral: Atividade Física no Ambiente de Trabalho". São Paulo: phorte, 2003.

MARTINS, C. O. Repercussão de um programa de ginástica laboral na qualidade de vida de trabalhadores de escritório. 2005. 184f. p. 21-82. Tese (Doutorado em Engenharia de Produção) - Programa de Pós-Graduação em Engenharia de Produção, Centro Tecnológico, Universidade Federal de Santa 
Catarina. Florianópolis, 2005.

MACIEL, R.H. et al. Quem se beneficia dos programas de ginástica laboral? Cadernos de Psicologia Social do Trabalho. Vol. 8, p.71-86, 2005.

MILITÃO, A. G. A influência da Ginástica Laboral para a Saúde dos trabalhadores e sua relação com os profissionais que a orientam. 2001. Dissertação (Mestrado em Engenharia de Produção), Universidade Federal de Santa Catarina, Florianópolis.

MOTA, M. R. et al. Musculação e ginástica na melhoria da saúde e qualidade de vida. In: Revista Digital Vida \& Saúde, Brasília, v.1, n.3, dez./jan. 2002.

OLIVEIRA, A. A. S. Os benefícios da ginástica laboral para a qualidade de vida de colaboradores: fatores motivacionais em foco. Disponível em: < http://arquivos.biblioceeteps.com.br/a/108546.pdf? $\mathrm{v}=201715020939>$. Acesso em 30 ago 2018.

PICOLI, E.B.; Guastelli, C. R. Ginástica laboral para cirurgiões dentistas. Phorte. São Paulo, 2002.

ROSSATO, L. C.; DUCA, G. F. D.; FARIAS, S. F.; NAHAS, M. V. Prática da ginástica laboral por trabalhadores das indústrias do Rio Grande do Sul Brasil. Revista Brasileira de Educação Física e Esporte. Vol.27 no.1, São Paulo Jan./Mar. 2013. Disponível em: < http://www.scielo.br/scielo.php?script=sci_arttext\&pid=S1807-

55092013000100003\&lang=pt >. Acesso em: 12 de jun de 2018.

SAMPAIO, A. A.; OLIVEIRA, J. R. G. A ginástica laboral na promoção da saúde e melhoria na qualidade de vida do trabalho. Disponível em: < http://saber.unioeste.br/index.php/cadernoedfisica/article/view/1649/1726 >. Acesso em: 06 jun. 2018. 